07

\title{
Влияние кристаллографической ориентации кремния на образование „первичных“ трещин
}

\author{
(C) В.И. Веттегрень ${ }^{1,2}$, А.Г. Кадомцев ${ }^{1}$, И.П. Щербаков ${ }^{1}$, Р.И. Мамалимов ${ }^{1,2}$, Г.А. Оганесян ${ }^{1}$ \\ ${ }^{1}$ Физико-технический институт им. А.Ф. Иофрфе РАН, \\ Санкт-Петербург, Россия \\ ${ }^{2}$ Институт фоизики Земли им. О.Ю. Шмидта РАН, \\ Москва, Россия \\ E-mail: Victor.Vettegren@mail.ru
}

Поступила в Редакцию 29 декабря 2021 г.

В окончательной редакции 29 декабря 2021 г.

Принята к публикации 3 января 2022 г.

При разрушении поверхности кремния образуются кластеры из самых мелких - „первичных“ трещин. Их образование приводит к появлению сигналов „фрактолюминесценции“ (FL). Сигналы и спектры FL содержали максимумы, число которых равно числу „первичных“ трещин в кластере. Анализ сигналов и спектров FL показал, что при разрушении поверхностей (100) и (110) появлялись кластеры из четырех, а поверхности (111) - из трех „первичных“ трещин. По скорости и времени роста оценены их размеры. Оказалось, что они кратны постоянной кристаллической решетки $a: \approx 3 a, 4 a$ и $6 a$. В момент образования „первичные“ трещины находятся в неравновесном состоянии и с течением времени трансформируются в дефекты, которые имеют вид „впадин“ и „вершинок“. Их размеры от 2 до 4 раз меньше размеров „первичных“ трещин.

Ключевые слова: кремний, разрушение, „первичные“ трещины, фрактолюминесценция, интерференционная профилометрия.

DOI: $10.21883 /$ FTT.2022.05.52337.268

\section{1. Введение}

Известно, что разрушение кристаллов под влиянием механических напряжений начинается с образования, накопления и объединения трещин [1-4]. Самые мелкие из них „первичные“ или „зародышевые“, образуются при прорыве дислокациями барьеров, которые препятствуют их движению по плоскостям скольжения [5-7].

В работах [8-10] для обнаружения и исследования „первичных“ трещин на поверхности (100) кристаллов кремния были использованы методы фрактолюминесценции (FL) с временным разрешением $2 \mathrm{~ns}$, интерференционной профилометрии белого света и фотолюминесценции. Нас заинтересовал вопрос: как влияет ориентация поверхности кремния на образование „первичных“ трещин“? Чтобы ответить на него исследовали сигналы и спектры FL, возникающие во время разрушения поверхностей (100), (110), (111), их профили и спектры PL после разрушения.

\section{2. Объект и методы исследования}

Исследовали „первичные“ трещины при разрушении поверхностей (100), (110) и (111) кристаллов кремния. Образец разрушали двумя способами. В первом - его вырезали алмазной пилой. Во втором способе FL возбуждали ударом по стальному бойку, установленному перпендикулярно поверхности образца.
Возникающее излучение (FL) кварцевой линзой фокусировали на поверхность катода фотоэлектронного умножителя РЕМ 136. Сигнал с его выхода подавался на вход аналогово-цифрового преобразователя ADS-3112 фирмы „АСТАСОМ“. Напряжение на его выходе через каждые 2 ns записывалось в память компьютера. Спектр FL регистрировали оптоволоконным спектрометром AvaSpec-ULSi2048L-USB2 OE.

Профили поверхности образцов получены на интерференционном оптическом профилометре белого света Zygo New View 6000 в УНУ „Физика, химия, и механика кристаллов и тонких пленок“ (ИПМаш РАН, СанктПетербург).

\section{3. Сигналы фрактолюминесценции при образовании „первичных“ трещин}

Приложение напряжений к кристаллам вызывает движение дислокаций по плоскостям скольжения [5]. При пересечении плоскостей образуются барьеры, препятствующие их движению. При прорыве барьеров, образуются мельчайшие „зародышевые те треины [6,7]. В процессе образования трещин из-за конфайнмента появляется FL [8-10].

Кристалл кремния обладает гранецентрированной кубической решеткой, и содержит 4 системы пересекающихся плоскостей скольжения дислокаций [111]. Поэтому спектры и сигналы FL должны содержать по 

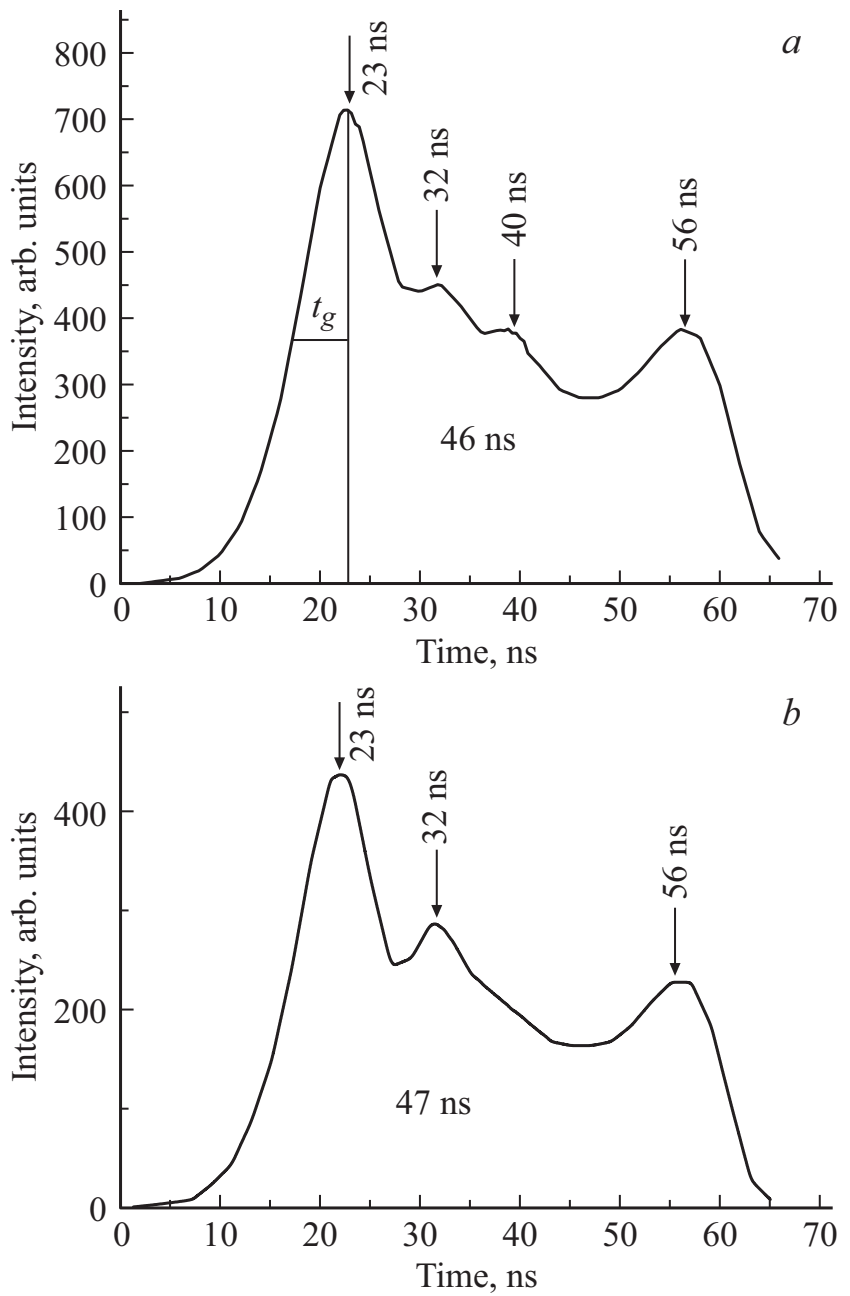

Рис. 1. Сигналы FL при разрушении поверхностей (100) (a) и $(111)-(b)$.

4 максимума, что и наблюдается в спектрах и сигналах FL поверхностей (100) и (110). Однако в спектрах и сигналах FL поверхности (111) наблюдали только три максимума (рис. 1).

Известно, что напряжение, действующее на дислокации, пропорционально произведению $m=\cos \chi \cdot \cos \lambda$, где $\lambda$ - угол между внешней силой и направлением скольжения, а $\chi-$ угол между силой и нормалью к плоскости скольжения (фактор Шмида) [11]. Первой появляется и растет быстрее остальных трещина, для которой значение фактора Шмида имеет наибольшую величину. В сигнале FL ей соответствует первый максимум в сигналах FL (рис. 1). Для остальных плоскостей $m$ меньше, что и приводит к уменьшению размеров „зародышевых“ трещин. Вероятно для направления (111) третий максимум соответствует трещинам, для которых $m \approx 0$.

Среднее время существования сигналов $\approx 47 \mathrm{~ns}$. Первый максимум появляется через $\approx 23$ ns после начала формирования сигнала, второй и третий для поверхностей $(100)$ и $(110)-$ с интервалом $\approx 9$ ns между ними.
Таблица 1. Размеры длины берегов первичных трещин при разрушении поверхностей кремния

\begin{tabular}{c|c|c|c|c}
\hline Ориентация & \multicolumn{4}{|c}{ Размеры трещины, $\mathrm{nm}$} \\
\hline$(100)$ & $4(6)^{*}$ & $2.6(4)^{*}$ & $2.1(3)^{*}$ & $2.0(3)^{*}$ \\
$(110)$ & $4(6)^{*}$ & $2.6(4)^{*}$ & $2.0(3)^{*}$ & $1.9(3)^{*}$ \\
$(111)$ & $4(6)^{*}$ & $2.6(4)^{*}$ & $?$ & $2.0(3)^{*}$
\end{tabular}

Пр и м е ч н и е. В скобках приведены значения $l / a$.

Таблица 2. Энергия максимумов полос в спектрах FL кремния

\begin{tabular}{c|l|l|l|l}
\hline Поверхность & \multicolumn{4}{|c}{ Энергия, $\mathrm{eV}$} \\
\hline$(100)$ & 1.4 & 1.6 & 1.8 & 2.3 \\
$(110)$ & 1.4 & 1.7 & 1.9 & 1.9 \\
$(111)$ & 1.41 & 1.6 & 1.7 & 2.1
\end{tabular}

Наконец последний сигнал FL для всех поверхностей наблюдается через $33 \mathrm{~ns}$ после первого.

Первый максимум всегда самый интенсивный, а, значит, и размер первой трещины больше остальных. Среднее время роста интенсивности первого максимума (на
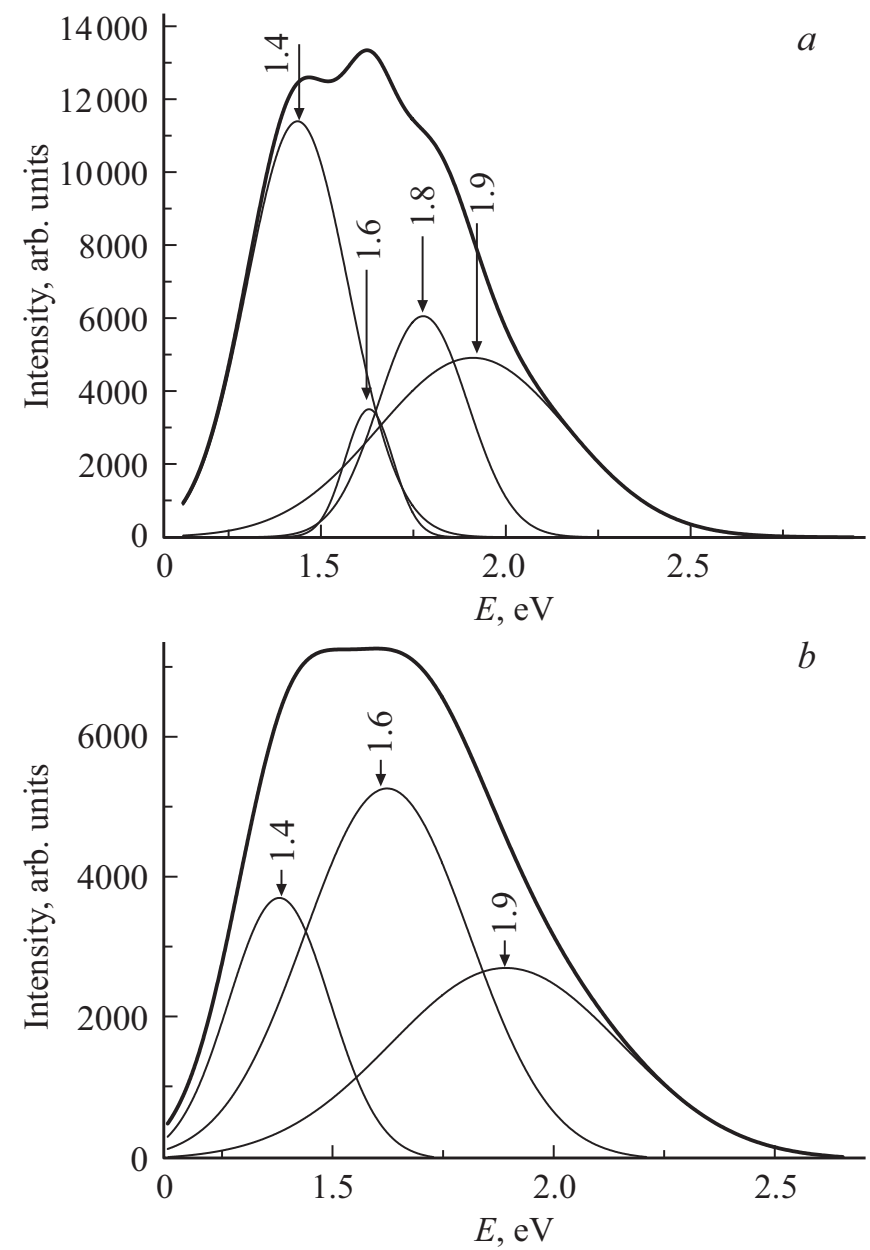

Рис. 2. Спектры FL поверхностей $(100)-(a)$ и $(111)-(b)$. 

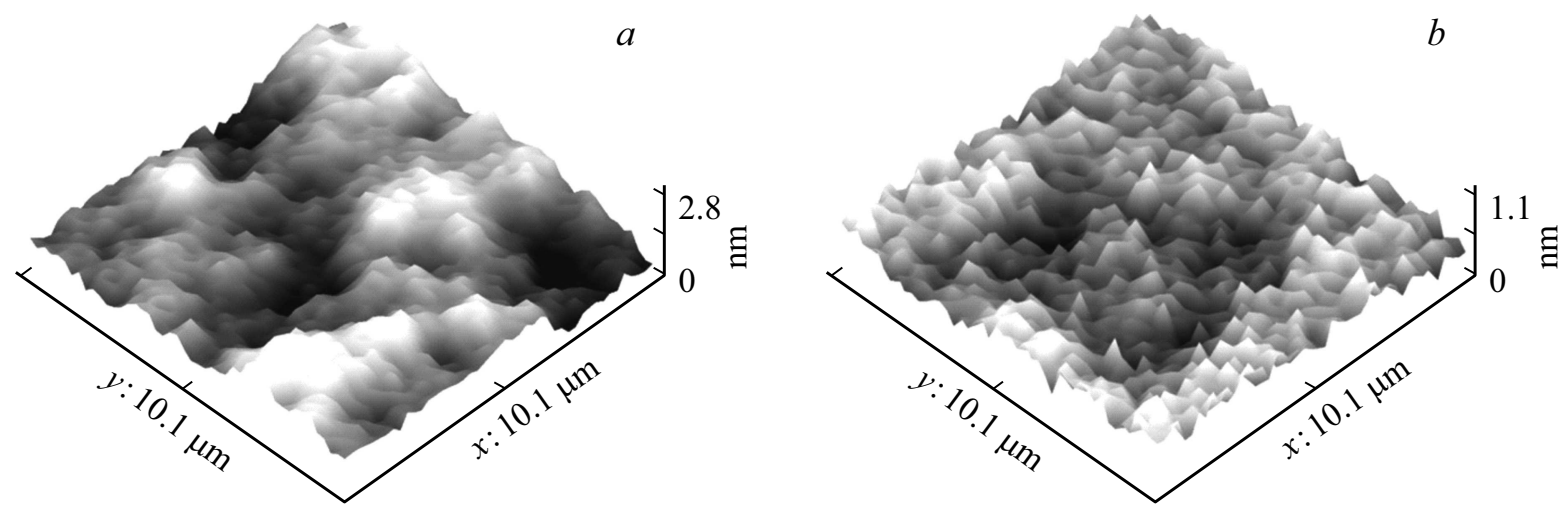

Рис. 3. Поверхности $(100)-(a)$ и $(111)-(b)$.

половине его интенсивности) $t_{g} \approx 8 \mathrm{~ns}$ (рис. 1). Предположим, что она равна средней скорости внедрения бойка в кремний. В наших опытах эта скорость $\approx 0.5 \mathrm{~nm} / \mathrm{ns}$. За $8 \mathrm{~ns}$ размер $l$ трещины достигает $\approx 0.5 \mathrm{~nm} / \mathrm{ns} \cdot 8 \mathrm{~ns}$ $=4 \mathrm{~nm}$. Размер второй трещины в $\approx 1.5$ раза меньше первой и равен $\approx 2.6 \mathrm{~nm}$. Размер третьей (для направлений кристаллической ячейки (100) и (110)) и последней трещины для всех трех направлений в $\approx 1.9$ раза меньше первой и равен $\approx 2 \mathrm{~nm}$ (табл. 1 ).

Постоянная (параметр) кристаллической решетки кремния $a=0.543 \mathrm{~nm}$ [12]. Если вычислить величину отношения размера $l$ к $a$, то можно видеть, что длина берегов трещин изменяется приблизительно кратно постоянной решетки и имеет значения $\approx 3 a, 4 a$ и $6 a$ (табл. 1 ). Столь малые значения размеров трещин оправдывает их отнесение к „первичным

\section{4. Спектры фрактолюминесценции при разрушении кремния}

На рис. 2 приведены спектры FL, возникающей при образовании „первичных“ трещин. В спектрах FL поверхностей (100) и (110) наблюдается 4 полосы: 1.4, 1.6, 1.8 и $1.9 \mathrm{eV}$, а поверхности $(111)-3: 1.4,1.6$ и $2 \mathrm{eV}$ (рис. 2, табл. 2). Отметим, что полоса $1.8 \mathrm{eV}$ отсутствует в спектрах FL поверхности (111). Как уже отмечалось в сигналах FL максимум при $39 \mathrm{~ns}$ также отсутствует. Вероятно, эта полоса может быть приписана трещинам, которые образуются через $39 \mathrm{~ns}$ после начала образования кластера. Отнесение остальных полос в спектрах ФЛ не ясно.

\section{5. Дефекты после релаксации трещин на поверхностях кремния}

„Первичные“ трещины находятся в неравновесном состоянии. С течением времени напряжения около трещин релаксируют, и на их месте образуются дефекты, которые наблюдали методом интерференционной профилометрии. На рис. 3 показаны поверхности (100) и (111) образцов кремния после разрушения. Обе поверхности содержат множество дефектов: „вершинок“ и впадин. Они, по-видимому, образовались при релаксации „первичных“ трещин.

Чтобы найти распределение вершинок по высоте, проводили сечение поверхностей параллельно оси $X$
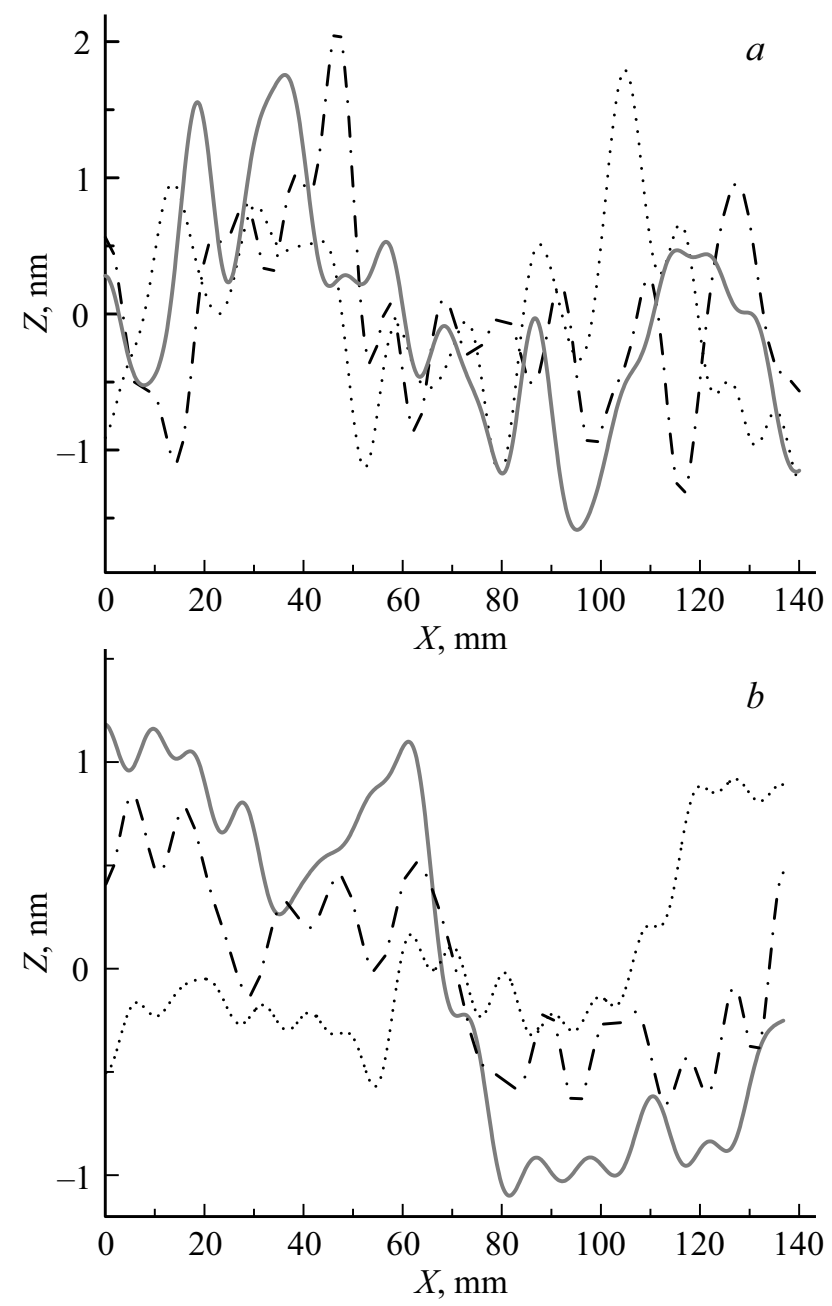

Рис. 4. Профили сечения поверхностей $(100)-(a)$ и $(111)-(b)$ параллельно оси $X$. 

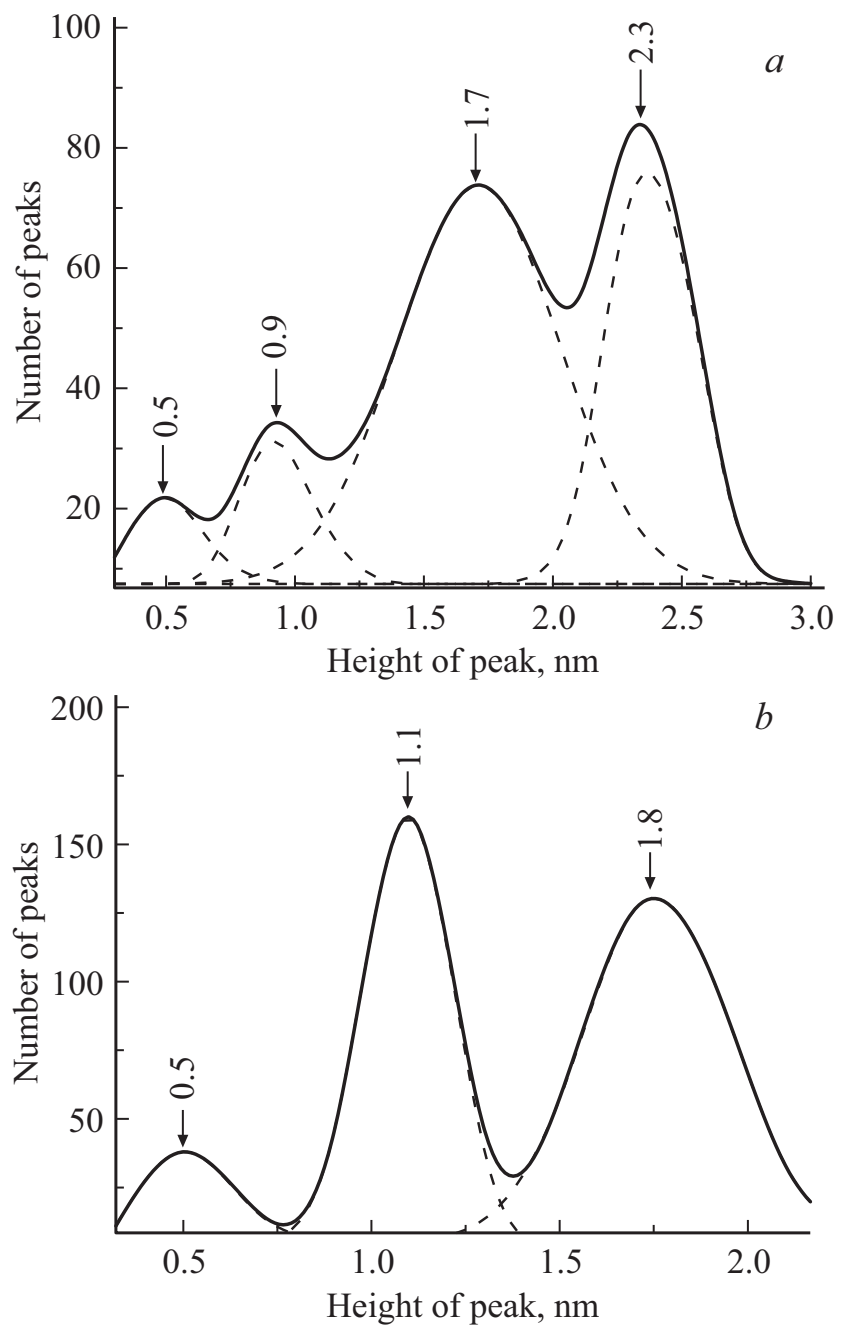

Рис. 5. Распределение высоты структурных образований на поверхностях кремния $(100)-(a)$ и $(111)-(b)$.

(рис. 4). Оказалось, что на поверхностях (100) и (110) оно представляло сумму из четырех гауссовых распределений дефектов, высота $h$ которых варьировала от $\approx 0.6$ до $\approx 2.3 \mathrm{~nm}$ (рис. 5, $a$, табл. 3). В то же время распределение высот пирамидок на поверхности (111) содержало только 3 гауссовых распределения

Таблица 3. Высота структурных нанодефектов на поверхностях (100) и (111)

\begin{tabular}{c|c|c|c}
\hline Поверхность & $(100)$ & $(110)$ & $(111)$ \\
\hline № вершинки & \multicolumn{3}{|c}{ Высота, $\mathrm{nm}$} \\
\hline 1 & $0.5(0.9)^{*}$ & $0.5(0.9)^{*}$ & $0.5(0.8)^{*}$ \\
2 & $1.0(1.4)^{*}$ & $0.9(1.4)^{*}$ & $1.1(1.7)^{*}$ \\
3 & $1.6(2.6)^{*}$ & $1.7(2.6)^{*}$ & $1.8(2.8)^{*}$ \\
4 & $2.4(3.5)^{*}$ & $2.3(3.5)^{*}$ & -
\end{tabular}

Пр и ме чани е. В скобках приведены значения $l / a$. (рис. 5, $b$ ). Их высота изменялась от $\approx 0.5$ до $1.8 \mathrm{~nm}$ (табл. 3).

Из рассмотрения рис. 5, и табл. 3 , следует, что высота вершинок структурных образований меньше размеров „первичных“ трещин в 2-4 раза.

\section{6. Выводы}

1. При разрушении поверхностей (100), (110) и (111) кремния образуются „первичные“ трещины, размер $l$ которых изменяется кратно постоянной решетки $a$ : $3 a$; $4 a$ и $6 a$.

2. С течением времени напряжения около первичных трещин релаксируют и на их месте образуются дефекты в виде „пирамидок“, размер которых в 2-4 раза меньше размеров ,первичных“ трещин.

\section{Конфликт интересов}

Авторы заявляют, что у них нет конфликта интересов.

\section{Список литературы}

[1] П.Г. Черемской, В.В. Слезов, В.И. Бетехтин. Поры в твердом теле. Энергоатомидат, М. (1990). 376 с.

[2] В.И. Бетехтин, А.Г. Кадомцев. ФТТ 47, 5, 801 (2005).

[3] В.Р. Регель, А.И. Слуцкер, Э.Е. Томашевский. Кинетическая природа прочности твердых тел. Наука, М. (1974). $560 \mathrm{c}$.

[4] В.А. Петров, А.Я. Башкарев, В.И. Веттегрень. Физические основы прогнозирования долговечности конструкционных материалов. Политехника, СПб (1993). 475 с.

[5] А.Н. Орлов. Введение в теорию дефектов в кристаллах. Высш. шк., М. (1983). 144 с.

[6] A.H. Cottrell. Theory of Crystal Dislocations. Gordon and Breach, N.Y. (1964). 91 p.

[7] В.И. Владимиров. Физическая природа разрушения металлов. Металлургия, М. (1984). 280 с.

[8] В.И. Веттегрень, Р.И. Мамалимов, И.П. Щербаков, В.Б. Кулик. ФТТ 62, 1070 (2020). DOI: $10.21883 /$ FTT.2020.07.49475.041.

[9] V.I. Vettegren, A.V. Ponomarev, R.I. Mamalimov, I.P. Scherbakov, V.B. Kulik. J. Phys.: Conf. Ser. 012142, 1697 (2020). DOI: 10.1088/1742-6596/1697/1/012142.

[10] В.И. Веттегрень, А.Г. Кадомцев, И.П. Щербаков, Р.И. Мамалимов, Г.А. Оганесян. ФТТ 63, 1594 (2021). DOI: 10.21883/FTT.2021.10.51410.122.

[11] E. Schmid, V. Boas. Kristallplastizität mit Besonderer Berücksichtigung der Metalle. Springer, Berlin (1935). 316 c.

[12] O. Bisi, S. Ossicini, L. Pavesi. Surface Sci. Rep. 38, 1 (2000).

Редактор Д.В. Жуманов 